\title{
Wpływ obróbki cieplnej na właściwości mechaniczne staliwa L20HNM
}

\section{Analysis of heat treatment influence on mechanical properties of L2OHNM cast steel}

\section{Streszczenie}

W pracy przedstawiono badania właściwości mechanicznych dwóch wytopów staliwa L20HNM o różnym składzie chemicznym i poddanych różnym procesom obróbki cieplnej. Dodatkowo przeprowadzono badania fraktograficzne przełomów udarnościowych i po próbie statycznego rozciągania. Badania wykazały znaczną różnicę we właściwościach mechanicznych w zależności od zastosowanej obróbki cieplnej. Pozwoli to na optymalizację wytwarzania staliw klasy L20 oraz prawidłowy dobór technologii i parametrów spawania odlewów.

Słowa kluczowe: staliwo; obróbka cieplna; właściwości mechaniczne

\section{Abstract}

The paper presents diversity of mechanical properties of L2OHNM cast steel contingent on applied heat treatment. Research also includes surface analysis of fractured tensile strength and impact test specimens. Results of investigation of influence of chemical composition paired with proper heat treatment. This will optimize the preparation of $L 20$ type cast steels and the correct choice of technology and welding parameters castings.

Keywords: cast steel; heat treatment; mechanical properties

istnieje konieczność spawania odlewów. Wysokie parametry pracy urządzeń energetycznych wymagają wykonania złączy spawanych o wysokiej jakości i wytrzymałości. Wynika stąd konieczność właściwego doboru techniki

Tablica I. Skład chemiczny wytopu, \%

Table I. Chemical composition of melt, \%

\begin{tabular}{|c|c|c|c|c|c|c|c|c|c|c|c|}
\hline \multirow{2}{*}{$\begin{array}{c}\text { Wytop } \\
1\end{array}$} & C & $\mathrm{Cr}$ & $\mathrm{Si}$ & Mn & $\mathrm{Ni}$ & Mo & Al & $\mathrm{Ti}$ & $\mathrm{Zr}$ & S & $\mathbf{P}$ \\
\hline & 0,070 & 1,17 & 0,245 & 0,139 & 1,09 & 0,596 & 0,184 & 0,002 & 0,017 & 0,024 & 0,024 \\
\hline \multirow{2}{*}{$\begin{array}{c}\text { Wytop } \\
2\end{array}$} & C & $\mathrm{Cr}$ & Si & Mn & $\mathrm{Ni}$ & Mo & Al & $\mathrm{Ti}$ & $\mathrm{Zr}$ & $S$ & $\mathbf{P}$ \\
\hline & 0,169 & 1,03 & 0,276 & 0,471 & 1,08 & 0,619 & 0,003 & 0,005 & 0,014 & 0,023 & 0,027 \\
\hline
\end{tabular}

Tablica II. Parametry zastosowanej obróbki cieplnej Table II. Heat treatment parameters

\begin{tabular}{|c|c|c|c|c|}
\hline Proces technologiczny & Medium chłodzące & Temp. & Czas nagrzewania & Czas wygrzewania \\
\hline Normalizacja/Studzenie & $\begin{array}{c}\text { Powietrze spokojne/ } \\
\text { wymuszone }\end{array}$ & 920 & $1.5 \mathrm{~h}$ & $20 \mathrm{~min}$ \\
\hline \multirow{2}{*}{ Hartowanie } & Olej & 920 & $1,5 \mathrm{~h}$ & $20 \mathrm{~min}$ \\
\cline { 2 - 5 } & Woda & 920 & $1,5 \mathrm{~h}$ & $20 \mathrm{~min}$ \\
\hline Odpuszczanie & Powietrze spokojne & 600 & $1 \mathrm{~h}$ & $30 \mathrm{~min}$ \\
\hline
\end{tabular}

Dr hab. inż. Jacek Słania, prof. IS - Instytut Spawalnictwa; dr hab. inż. Grzegorz Golański, prof. PCz - Politechnika Częstochowska; mgr inż. Maciej Woszek - Doosan Babcock Energy Polska Sp. z o.o.

Autor korespondencyjny/Corresponding author: maciejwoszek@gmail.com 
i parametrów spawania, a także materiałów dodatkowych oraz temperatury ewentualnej obróbki cieplnej. Niewątpliwie wpływa na to proces metalurgiczny, proces odlewania i obróbka cieplna odlewów. Prawidłowy dobór parametrów zabiegów technologicznych pozwala uzyskać staliwo o własnościach nie gorszych od własności nowoczesnych stali ulepszanych cieplnie czy obrabianych termomechanicznie.

\section{Badania własne}

Badaniom poddano dwa wytopy staliwa L2OHNM wykonane w tyglowym piecu próżniowym z wyłożeniem obojętnym. Przy prowadzeniu drugiego wytopu przeprowadzono modyfikację składu chemicznego, dodając FeMn, FeSi oraz mikrododatki: FeTi i FeZr [3]. Skład chemiczny wytopów przedstawiono $\mathrm{w}$ tablicy $\mathrm{I}$.

Staliwo z obu wytopów po odlaniu poddano wyżarzaniu normalizującemu, a następnie odlane w pierwszym wytopie zostało poddane ulepszaniu cieplnemu, a z drugiego hartowaniu. Zabiegi hartowania zostały przeprowadzone w różnych ośrodkach chłodzących; próbki z pierwszego wytopu hartowano w oleju, a z drugiego w oleju i wodzie. Badane odlewy poddano również studzeniu na powietrzu (tabl.II).

\section{Badania właściwości mechanicznych}

Badania właściwości mechanicznych obejmowały: pomiar twardości metodą Brinell'a, statyczną próbę rozciągania i próbę udarności. Pomiar twardości przeprowadzono metodą Brinell'a przy obciążeniu 750 kG kulką z węglików spiekanych o średnicy $5 \mathrm{~mm}$. Statyczną próbę rozciągania wykonano na standardowych próbkach (PN-EN ISO 68691:2010) na maszynie wytrzymałościowej VEB Lipsk a próbę udarności na młocie Charpy'ego o zakresie pomiarowym do $150 \mathrm{~J}$, używając standardowych próbek z naciętym na głębokość $2 \mathrm{~mm}$ karbem Messnagera. Wyniki pomiarów przedstawiono na rysunkach $1 \div 4$.

\section{Średnia twardość, HB 5/750}

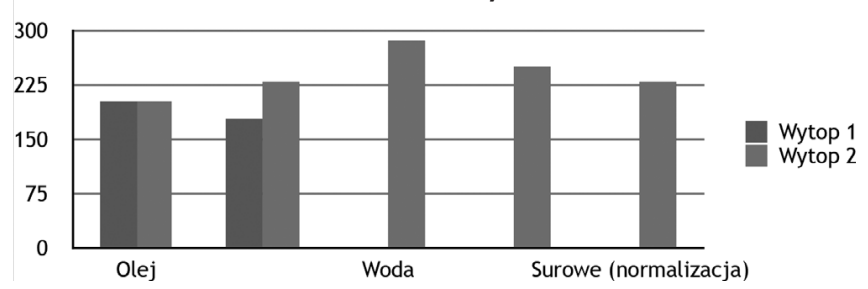

Rys. 1. Porównanie średnich twardości wytopu 1 i 2

Fig. 1. Comparison of median hardness of melt 1 and 2

\section{Pomiary twardości}

Twardość materiału pochodzącego z wytopu pierwszego po hartowaniu w oleju, w porównaniu do materiału po studzeniu na powietrzu wraz z późniejszym odpuszczaniem była wyższa o około $24 \mathrm{HB}$, co było spowodowane powstaniem struktury nierównowagowej. W wytopie drugim, gdzie zostało przeprowadzone tylko hartowanie, twardość w przypadku zastosowania oleju jako medium chłodzącego jest taka sama jak dla wytopu pierwszego. Różnicę twardości można zaobserwować przy studzeniu na powietrzu. Wytop drugi wykazywał twardość wyższą o 49 HB. Wynikać to może z wyższej zawartości węgla, co skutkuje większym udziałem perlitu w strukturze. Najwyższą twardość, wynosząca $286 \mathrm{HB}$, miało staliwo hartowane w wodzie,. Hartowanie w wodzie przyczynia się do powstania struktur „iglastych" - martenzytycznych. Warto zauważyć, że surowe staliwo (nie poddane obróbce cieplnej) z wytopu drugiego wykazało twardość na poziomie $250 \mathrm{HB}$, a poddane normalizacji 229 HB.

\section{Średnia udarność KCU,}

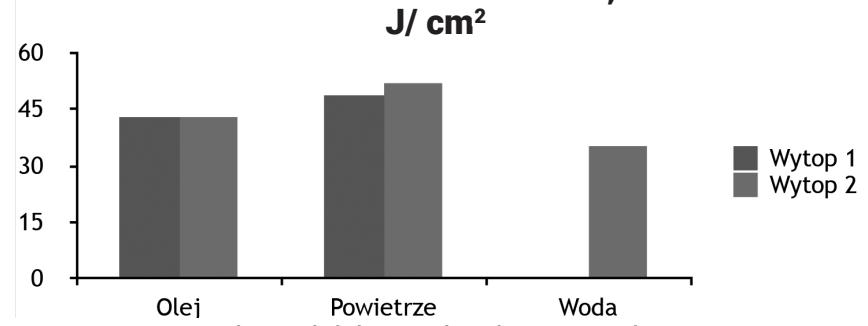

Rys. 2. Porównanie średnich twardości wytopu 1 i 2

Fig. 2. Comparison of median hardness of melt 1 and 2

\section{Próba udarności}

Najwyższą udarnością cechują się próbki studzone na powietrzu; dla próbek z wytopu pierwszego wynosi ona 49 $\mathrm{J} / \mathrm{cm}^{2}$, a dla drugiego $52 \mathrm{~J} / \mathrm{cm}^{2}$. Próbki hartowane w oleju nie wykazały zmiany udarności i pozostała na stałym poziome $43 \mathrm{~J} / \mathrm{cm}^{2}$ w badanych wytopach. Najmniejszą udarnością $35 \mathrm{~J} / \mathrm{cm}^{2}$ charakteryzowało się staliwo po hartowaniu w wodzie. Udarność podobnie jak twardość jest ściśle związana z strukturą badanego materiału, co z kolei zależy od parametrów procesu obróbki cieplnej. Hartowanie w wodzie pozwoliło na powstanie struktur hartowniczych charakteryzujących się wysoką wytrzymałością kosztem obniżonej plastyczności i ciągliwości. Studzenie na powietrzu sprzyjało uzyskaniu struktury o wyższej plastyczności i ciągliwości, kosztem niższych właściwości wytrzymałościowych. Hartowanie w oleju pozwala na powstanie struktury pośredniej - bainitycznej cechującej się dobrymi parametrami wytrzymałościowymi przy zadowalającej plastyczności.

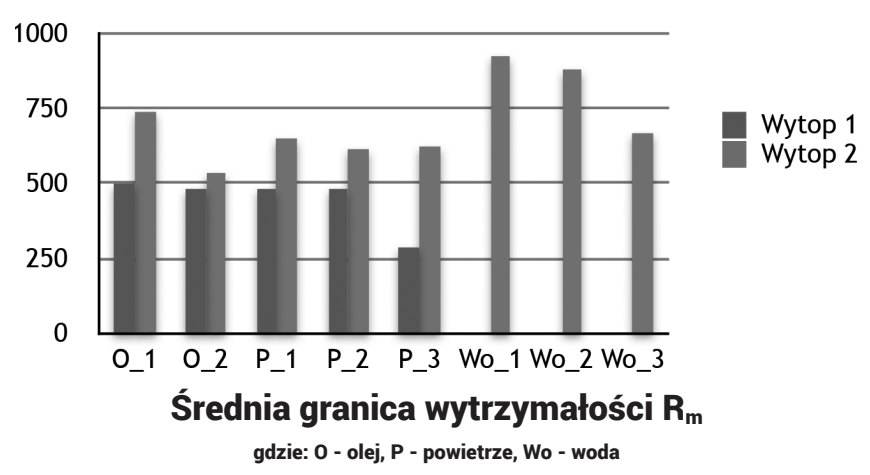

Rys. 3. Porównanie wyników wytrzymałości na rozciąganie $R_{m}$ Fig. 3. Comparison of median ultimate yield strength of melt

\section{Statyczna próba rozciągania}

Rysunek 3 przedstawia wyniki pomiarów wytrzymałości na rozciąganie $\mathrm{Rm}$ badanych wytopów. Próbki hartowane w oleju dla wytopu drugiego osiągają wartość $R_{m}$ około 742 $\mathrm{MPa}$, a dla pierwszego około $480 \mathrm{MPa}$. Próbki studzone na wolnym powietrzu również wykazują wzrost wartości $R_{m}$ w wytopie drugim o średnio $175 \mathrm{MPa}$. Próbki hartowane w wodzie, cechują się najwyższą wartością $R_{m}$, wynoszącą $928 \mathrm{MPa}$ w przypadku próbki z wytopu drugiego. Znaczna różnica w uzyskanych wynikach jest spowodowana skorygowanym składem chemicznym, szczególnie zawartością węgla oraz obróbką cieplną.

W próbie rozciągania określono również właściwości plastyczne, tj. wydłużenie A i przewężenie Z (rys.4). Średnia różnica wartości wydłużenia pomiędzy wytopami w przypadku hartowaniu w oleju i studzeniu na powietrzu wynosi 
$5 \%$, a przewężenia $10 \%$ na korzyść wytopu drugiego. Wartość A i Z próbek hartowanych w wodzie wynosi $12 \%$. Najwyższe wartości właściwości plastycznych uzyskano dla wytopów studzonych w spokojnym powietrzu, natomiast najgorsze wyniki uzyskano dla materiału poddanego hartowaniu w wodzie.

\section{Badania fraktograficzne}

Makroskopowe obrazy przełomów próbek przedstawiono w tablicy III i IV. Główną różnicą pomiędzy dwoma wytopami jest wielkość ziarna widoczna na przełomach. Wytop drugi wykazuje strukturę o mniejszym ziarnie niż wytop pierwszy, niezależnie od zastosowanego medium chłodzącego. Różnice w uzyskanych wynikach wartości wytrzymałości na rozciąganie, właściwości plastycznych czy udarności pomiędzy dwoma wytopami, znajduje również uzasadnienie w wpływie wielkości ziarna na właściwości mechaniczne zgodnie z zależnością Halla-Petcha [4].

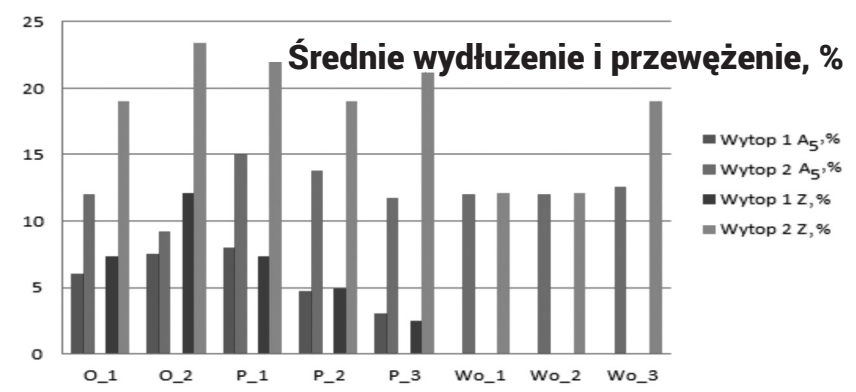

Rys. 4. Porównanie wyników wydłużenia i przewężenia wytopów 1 i 2 Fig. 4. Comparison of elongation and contraction of melt 1 and 2

Tablica III. Zdjęcia przełomów próbek udarnościowych z wytopów 1 i 2

Table III. Images of fractured impact test specimens from melt 1 and 2

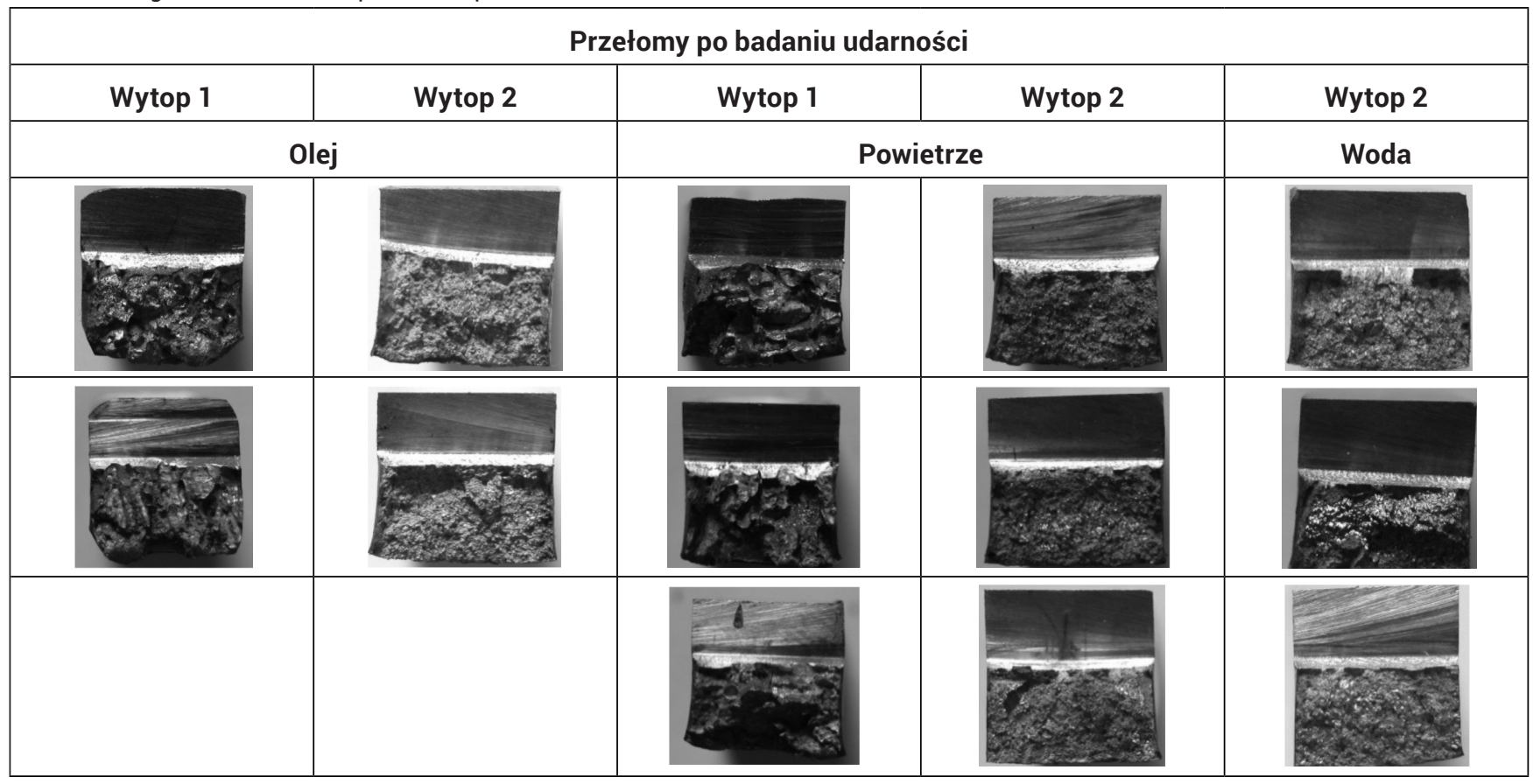

Tablica IV. Zdjęcia przełomów po próbie statycznego rozciągania wytopów 1 i 2 Table IV. Images of fractured tensile strength test specimens from melt 1 and 2

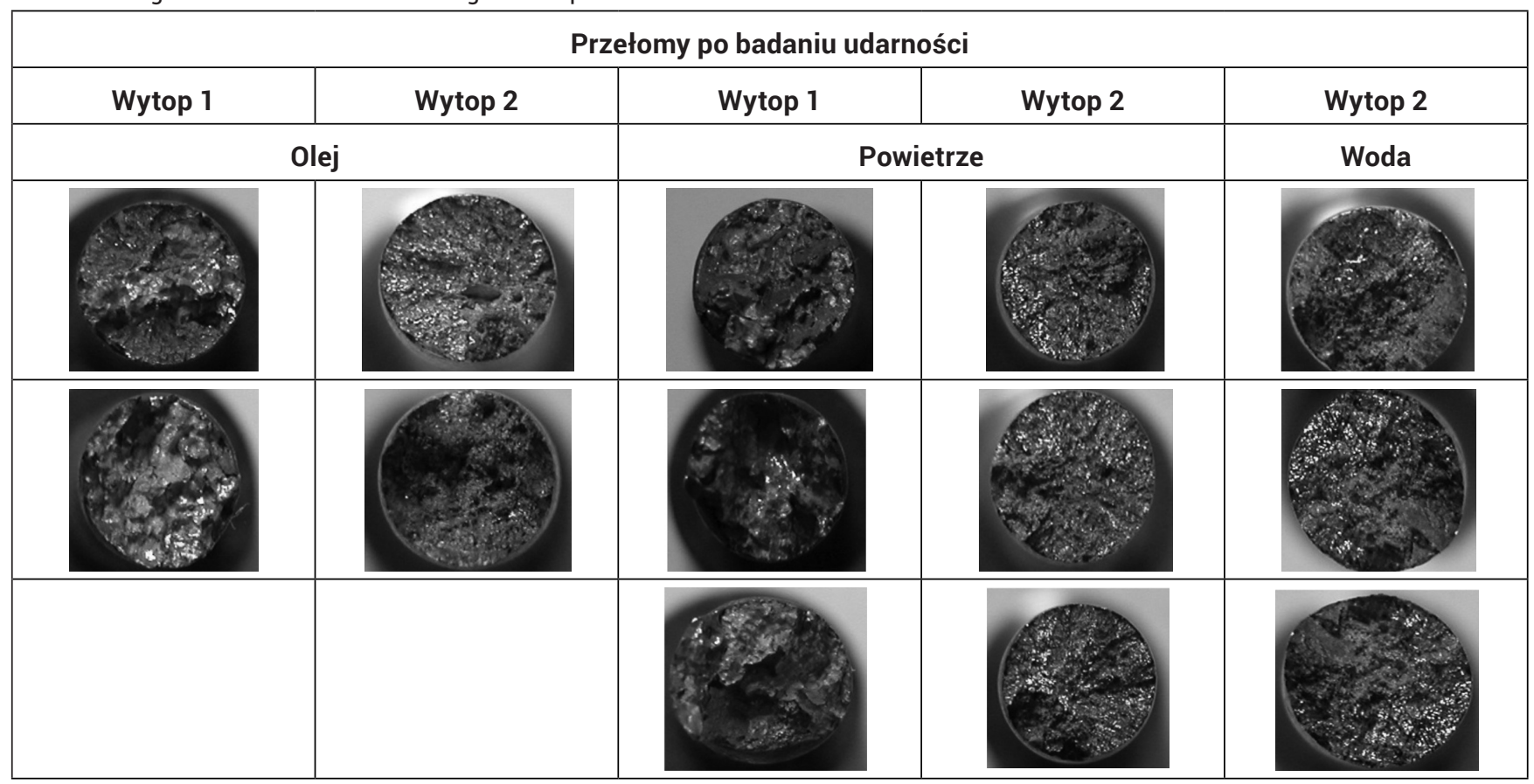




\section{Wnioski}

W przypadku staliwa L20HNM hartowanie z zastosowaniem wody jako medium chłodzącego pozwala osiągnąć wysokie właściwości wytrzymałościowe przy zadowalających własnościach plastycznych.

Ulepszanie cieplnie, takie jakie zostało zastosowane w wytopie 1 może prowadzić do zbyt dużego obniżenia twardości i doraźnej wytrzymałości na rozciąganie. Zalecane jest stosowanie jedynie hartowania lub utwardzania cieplnego w celu uzyskania jak najlepszych właściwości mechanicznych.

Czystość metalurgiczna stopu ma istotny wpływ na właściwości mechaniczne i spawalność stopu.

Zastosowanie odpowiedniej obróbki cieplnej jest bardzo ważne ze względu na skłonność staliwa do rozrostu ziarna. Główną różnicą pomiędzy badanymi wytopami, oprócz zawartości węgla jest wielkość ziarna, co wpłynęło na uzyskane wyniki.

Dalsze prace badawcze nad tym typem staliwa powinny się skupiać na dodatku większej ilości C i Mn, przeprowadzeniu utwardzania cieplnego (z wcześniejszą normalizacją) lub tylko normalizowaniem i późniejszym hartowaniem staliwa. Pozwoli to uzyskać znacznie wyższe właściwości wytrzymałościowe kosztem niewielkiego spadku udarności i spawalności badanego staliwa.

\section{Literatura}

[1] J.Głownia, B.Kalandyk, R.Zapała, S.Sobula, G.Tęcza, P.Malatyńska, I. Telejko, M. Brzeziński Charakterystyka stali na odlewy, Wydawnictwa AGH, Kraków 2010.

[2] Praca zbiorowa pod red. E.Turyka Technologia spawania i napawania stali, staliwa i żeliwa, Instytut Spawalnictwa, Gliwice 1996.
[3] D.Bartocha, Cz.Baron, J.Suchoń, J.Kilarski, J.Szajnar. Wpływ dodatków modyfikujących na własności staliwa niskostopowego; Archives of Foundry Engineering Volume 12 Special Issue 2/2012.

[4] Hanamura T., Qiu H. Analysis of Fracture Toughness Mechanism in Ultrafine-grained Steels, 2014 